\title{
Some Properties of Soft Delta-Topology
}

\author{
1Ramadhan A. Mohammed, 2O. R. Sayed, ${ }^{3}$ A. Eliow \\ 1Department of Mathematics, College of Basic Education, University of Duhok, Kurdistan-Region - Iraq \\ 2Department of Mathematics, Faculty of Science, Assiut University, Assiut-Egypt \\ ${ }^{3}$ Department of Mathematics, Faculty of Science, Sohag University, Sohag-Egypt
}

\begin{abstract}
In this paper, we apply the concept of soft sets to $\delta$-open set and $\delta$-closed set. The associated soft $\delta$-topology in terms of soft $\delta$-open sets were introduced and some properties of them were investigated. Moreover, the definitions, characterizations and basic results concerning soft $\delta$-interior, soft $\delta$-closure, soft $\delta$-boundary and soft $\delta$-exterior were given. Finally, the concept of soft pu- $\delta$ - continuity was defined and some properties of it were introduced.
\end{abstract}

Keywords: Soft set; soft $\delta$-open set; soft $\delta$-topology; soft pu- $\delta$-continuity.

\section{Introduction}

Some concepts in mathematics can be considered as mathematical tools for dealing with uncertainties, namely theory of vague sets, theory of rough sets and etc. But all of these theories have their own difficulties. The concept of soft sets was first introduced by Molodtsov as a general mathematical tool for dealing with uncertain objects (Dmitriy Molodtsov, 1999). He successfully applied the soft theory in several directions, such as smoothness of functions, game theory, probability, Perron integration, Riemann integration, theory of measurement(Dmitriy Molodtsov, 1999; DA Molodtsov, 2001; D Molodtsov, 2004; D Molodtsov, Leonov, \& Kovkov, 2006). It is remarkable that, Molodtsov used this concept in order to solve complicated problems in other sciences such as, engineering, economics and etc. The soft set theory has been applied to many different fields. Later, few researches((Aygünoğlu \& Aygün, 2012),(Çağman, Karataş, \& Enginoglu, 2011),(Georgiou \& Megaritis, 2014),(Hussain \& Ahmad, 2011),(Min, 2011),(Peyghan,

Academic Journal of Nawroz University

(AJNU) Volume 8, No 4 (2019).

Regular research paper : Published 28 Dec 2019

Corresponding author's e-mail : Ramadhan.hajani@uod.ac Copyright @2018 ${ }^{1}$ Ramadhan A. Mohammed, 2O. R. Sayed, ${ }^{3} \mathrm{~A}$. Eliow. This is an open access article distributed under the Creative Commons Attribution License.
Samadi, \& Tayebi),(Shabir \& Naz, 2011),(Zorlutuna, Akdag, Min, \& Atmaca, 2012)) introduced and studied the notion of soft topological spaces. Recently, in (2014), S. Yüksel, N. Tozlu and Z. G. Ergül (Ergül, Yüksel, \& Tozlu, 2014) initiated soft regular open set and soft regular closed set.

\section{Preliminaries}

We present here the basic definitions and results related to soft set theory that will be needed in the sequel.

Definition 2.1.(Dmitriy Molodtsov, 1999) Let $X$ to be as an initial universe and $\mathrm{E}$ as set of parameters, and $P(X)$ be denoted as the power set of X. A pair $(F, A)$ is referred to as a soft set over $\mathrm{X}$, where $F$ is a mapping given by $F: A \rightarrow P(X)$ where and $A \sqsubset E$. On the other hand, a soft set over $X$ is a parameterized family of subsets of the universe $X$, for $\varepsilon \in A, F(\varepsilon)$ might be recognized as the set of $\varepsilon$-approximate elements of the soft set $(F, A)$. The set of all these soft sets over $\mathrm{X}$ denoted by $S S(X)_{A}$.

Definition 2.2.(Maji, Biswas, \& Roy, 2003). $\operatorname{Let}(F, A),(G, B) \in S S(X)_{E}$. Then $(F, A)$ is a soft subset of $(G, B)$, denoted $\operatorname{by}(F, A) \subseteq(G, B)$, if (i) $A \subseteq B$, (ii) $F(e) \subseteq G(e), \forall e \in A$. In this case, $(F, A)$ is said to be a soft subset of $(G, B)$ and $(G, B)$ is said to be a soft superset of $(F, A)$.

Definition 2.3.(Maji et al., 2003). Two soft subsets $(F, A)$ 
and $(G, B)$ over a common universe set $X$ are said to be soft equal if $(F, A)$ is a soft subset of $(G, B)$ and $(G, B)$ is a soft subset of $(F, A)$.

Definition 2.4.(Ali, Feng, Liu, Min, \& Shabir, 2009). The complement of a soft set $(F, A)$, denoted by $(F, A)^{c}$, is defined by $(F, A)^{c}=\left(F^{c}, A\right), \quad F^{c}: A \rightarrow P(X)$ is a functions given by $F^{c}(e)=X-F(e), \forall e \in A$. Clearly $\left((F, A)^{c}\right)^{c}$ is the same as $(F, A)$.

Definition 2.5. (Maji et al., 2003). A soft set $(F, E)$ over $X$ is said to be a null soft set, denoted by $0_{E}$ if $F(e)=$ $\emptyset, \forall e \in A$, A soft set $(F, E)$ over $X$ is said to be an absolute soft set, denoted by $1_{E}$ if $F(e)=X, \forall e \in E$

Definition 2.6. (Zorlutuna et al., 2012). The soft set $(F, A) \in S S(X)_{E}$ is called a soft point in $X$, denoted by $e_{F}$, if for the element $e \in E, F(e) \neq 0_{E}$ and $F\left(e^{\prime}\right)=$ $0_{E} \forall e^{\prime} \in E \backslash\{e\}$. The set of all soft points of $X$ is denoted by $S P(X)$. The soft point $e_{F}$ is said to be in the soft set $(G, E)$, denoted by $e_{F} \in(G, E)$, if for the element $e_{F} \in$ $E, F(e) \sqsubseteq G(e)$.

Definition 2.7. (Peyghan et al.; Shabir \& Naz, 2011). Let $X$ be an initial universe set, $E$ a set of parameters and $\tau \sqsubseteq S S(X)_{E}$. We say that the family $\tau$ a soft topology on $X$ if the following axioms are true.

(1) $0_{E}, 1_{E} \in \tau$.

(2) If $(G, E),(H, E) \in \tau$, then $(G, E) \sqcap(H, E) \in \tau$.

(3) If $(G i, E) \in \tau$ for every $i \in I$, then $\sqcup(G i, E): i \in I\} \in$ $\tau$. The triplet $(X, \tau, E)$ is called a soft topological space. The members of $\tau$ are called soft open sets in $X$. Also, a soft set $(F, E)$ is called soft closed set if the complement $\left(F^{c}, E\right)$ belongs to $\tau$. The family of all soft closed sets is denoted by $\tau^{c}$

Definition 2.8. (Zorlutuna et al., 2012). Let $(X, \tau, E)$ be a soft topological space and $(F, E) \in S S(X)_{E}$. A soft topology $\tau_{(F, E)}=\{(G, E) \sqcap(F, E):(G, E) \in \tau\}$ is called a soft relative topology of $\tau$ on $(F, E)$, and $\left((F, E), \tau_{(F, E)}\right)$ is called a soft subspace of $(X, \tau, E)$.

Definition 2.9. (Zorlutuna et al., 2012). A soft set $(G, E)$ in a soft topological space $(X, \tau, E)$ is called

(i) a soft neighborhoods of a soft point $F(e) \in(X, \tau, E)$ if there exists a soft open set $(H, E)$ such that $F(e) \in(H, E) \sqsubseteq(G, E)$.

(ii) a soft neighborhood of a soft set $(F, E)$ if there exists a soft open set $(H, E)$ such that $(F, E) \subseteq(H, E) \subseteq(G, E)$. The neighbourhood system of a soft point $F(e)$ denoted by $N_{\tau}(F(e))$, is the family of all its neighborhood.

Definition 2.11. (Peyghan et al.; Shabir \& Naz, 2011), (Zorlutuna et al., 2012) Let $(X, \tau, E)$ be a soft topological space and $(F, E) \in S S(X)_{E}$. The soft closure of $(F, E)[24]$ is the soft set $C l_{s}(F, E)=\sqcap\{(S, E):(S, E) \in$ $\left.\tau^{c},(F, E) \sqsubseteq(S, E)\right\}$.

The soft interior of $(F, E)[29]$ is the soft set $\operatorname{Int}_{s}(F, E)=$ $\sqcup\{(S, E):(S, E) \in \tau,(S, E) \sqsubseteq(F, E)\}$.

Theorem 3.12. (Zorlutuna et al., 2012). Let $(X, \tau, E)$ be a soft topological space and $(F, E),(G, E) \in S S(X)_{E}$. Then

(1) $\left(C l_{s}(G, E)\right)^{c}=\operatorname{Int}_{s}\left(G^{c}, E\right)$.

(2) $\left(\operatorname{Int}_{s}(G, E)\right)^{c}=C l_{s}\left(G^{c}, E\right)$.

Definition 2.13. (Ergül et al., 2014). Let $(X, \tau, E)$ be soft topological space and $(F, E)$ be a soft set over $X$ :

(1) $(F, E)$ is said to be a soft regular open set in $X$ if $(F, E)=\operatorname{Int}_{s}\left(C l_{S}(F ; E)\right.$, denoted by $(F, E) \in S R O(X, E)$.

(2) $(F, E)$ is said to be a soft regular closed set in $X$ if $(F, E)=C l_{S}\left(\operatorname{Int}_{S}(F, E)\right.$, denoted by $\left.(F, E) \in S R C(X, E)\right)$.

Remark 2.14. (Ergül et al., 2014). Every soft regular open set in soft topological space Let $(X, \tau, E)$ is soft open set.

Definition 2.15.(Zorlutuna et al., 2012). Let $(X, \tau, E)$ and $(Y, \rho, H)$ be soft topological spaces. Let $\mu: X \rightarrow Y$ and $p: E \rightarrow H$ be functions. Then the function $f_{p \mu}: S S(X)_{E} \rightarrow$ $S S(Y)_{H}$ is defined by:

(i) Let $(F, E) \in S S(X)_{E}$. The image of $(F, E)$ under $f_{p \mu}$, written $f_{p \mu}(F, E)=\left(\left(f_{p \mu} F\right), p(E)\right)$ is a soft set in $S S(Y)_{H}$ such that

$f_{p \mu}(F)=\left\{\begin{array}{cc}\sqcup_{x \in p^{-1}(y) \cap A} \mu(F(x)), p^{-1}(y) \sqcap A \neq \emptyset & \text { for all } \\ \emptyset, \text { othereise } & \end{array}\right.$ 
$y \in H$.

(ii) Let $(G, H) \in S S(Y)_{H}$. The inverse image of $(G, H)$ under $f_{p \mu}$, written as $f_{p \mu}^{-1}(G, H)=\left(f_{p \mu}^{-1}(G), p(H)\right)$ is soft set in $S S(X)_{E}$ such that

$f_{p \mu}^{-1}(G)=\left\{\begin{array}{cc}\mu^{-1}(G(p(x))), & p(x) \in H \\ \varnothing, & \text { othereise }\end{array}\right.$ for all $x \in E$.

\section{Soft regular open set and soft regular closed set}

In this section, we introduce some properties of the soft regular open set and soft regular closed set.

Theorem 3.1. Let $(X, \tau, E)$ be a soft topological space. Let $\left\{\left(F_{i}, E\right), i \in I\right\} \in S R O(X, E)$. Then.

(1) $\left(F_{1}, E\right) \sqcap\left(F_{2}, E\right) \in S R O(X, E)$.

$(2)\left(F_{1}, E\right) \sqcup\left(F_{2}, E\right) \notin S R O(X, E)$.

Proof. (1) Let ) $\left(F_{1}, E\right),\left(F_{2}, E\right) \in S R O(X, E)$. Then ) $\left(F_{1}, E\right) \sqsubseteq C l_{s}\left(F_{1}, E\right),\left(F_{2}, E\right) \sqsubseteq C l_{s}\left(F_{2}, E\right)$, and $\left(F_{1}, E\right) \sqcap$ $\left(F_{2}, E\right)$ is soft open set. We have $\operatorname{Int}_{s}\left(\left(F_{1}, E\right) \sqcap\left(F_{2}, E\right)\right)=$ $\operatorname{Int}_{s}\left(F_{1}, E\right) \sqcap \operatorname{Int}_{s}\left(F_{2}, E\right) . \quad$ Then $\operatorname{Int}_{s}\left(\left(F_{1}, E\right) \sqcap\left(F_{2}, E\right)\right) \sqsubseteq$ $\operatorname{Int}_{s} C l_{s}\left(\left(F_{1}, E\right) \sqcap \operatorname{Int}_{s}\left(F_{2}, E\right)\right)$, therefore $\quad\left(\left(F_{1}, E\right) \sqcap\right.$ $\left.\left(F_{2}, E\right)\right) \sqsubseteq \operatorname{Int}_{s} C l_{s}\left(\left(F_{1}, E\right) \sqcap \operatorname{Int}_{s}\left(F_{2}, E\right)\right)$. Conversely, pick $e_{F} \in \operatorname{Int}_{S} C l_{S}\left(\left(F_{1}, E\right) \sqcap \operatorname{Int}_{s}\left(F_{2}, E\right)\right)$.

Then there is a soft open set $(G, E)$ such that $e_{F} \in$ $(G, E) \sqsubseteq \operatorname{Int}_{S} C l_{s}\left(\left(F_{1}, E\right) \sqcap \operatorname{Int}_{s}\left(F_{2}, E\right)\right)$. This implies that $(G, E) \sqsubseteq C l_{s}\left(F_{1}, E\right) \quad$ and $\quad(G, E) \subseteq C l_{s}\left(F_{2}, E\right)$. Then $(G, E) \sqsubseteq \operatorname{Int}_{s} C l_{s}\left(F_{1}, E\right)=\left(F_{1}, E\right) \quad$ and $\quad(G, E) \sqsubseteq$ $\operatorname{Int}_{S} C l_{s}\left(F_{2}, E\right)=\left(F_{2}, E\right)$. In conclusion $(G, E) \sqsubseteq\left(F_{2}, E\right) \sqcap$ $\left(F_{2}, E\right)$, because $e_{F} \in(G, E)$ it follows that $e_{F} \in\left(F_{2}, E\right) \sqcap$ $\left(F_{2}, E\right)$ and we are done.

(2) It show by the following example

Example 3.2. Let $X=\left\{h_{1}, h_{2}, h_{3}\right\}, E=\left\{e_{1}, e_{2}\right\}$ and $\tau=$ $\left\{0_{E}, 1_{E},\left(F_{1}, E\right),\left(F_{2}, E\right),\left(F_{3}, E\right)\right\}$ be a soft topological space, where $\left(F_{1}, E\right)=\left\{\left(e_{1},\left\{h_{1}\right\}\right),\left(e_{2},\left\{h_{1}\right\}\right)\right\},\left(F_{2}, E\right)=$ $\left\{\left(e_{1},\left\{h_{2}\right\}\right),\left(e_{2},\left\{h_{2}\right\}\right)\right\},\left(F_{3}, E\right)=\left\{\left(e_{1},\left\{h_{1}, h_{2}\right\}\right),\left(e_{2},\left\{h_{1}, h_{2}\right\}\right)\right\}$

, then $\left(F_{1}, E\right),\left(F_{2}, E\right) \in S R O(X, E)$, but then $\left(F_{1}, E\right) \sqcup$ $\left(F_{2}, E\right) \notin S R O(X, E)$

Remark 3.4. A soft set $(F, E)$ in a soft topological space $(\mathrm{X}, \tau, \mathrm{E})$ is soft regular open set if and only if $\left(F^{c}, E\right)$ is soft regular closed set.
Corollary 3.5. Let $(X, \tau, E)$ be a soft topological space.

Let $\left\{\left(F_{i}, E\right), i \in I\right\} \in \operatorname{SRC}(X, E)$. Then.

(1) $\left(F_{1}, E\right) \sqcup\left(F_{2}, E\right) \in \operatorname{SRC}(X, E)$.

$(2)\left(F_{1}, E\right) \sqcap\left(F_{2}, E\right) \notin S R C(X, E)$.

Proof. (1) and (2) are obvious.

Remark 3.6. $0_{E}$ and $1_{E}$ are always soft regular open set and soft regular closed set.

Remark 3.7. Every soft regular open set is soft open set, but the converse is not true, which follows from the following example.

Example 3.8. The soft topological space is same in Example 3.2. Let $\left(F_{3}, E\right)$ is a soft open set but it is not a soft regular open set because $\operatorname{Int}_{s}\left(\mathrm{Cl}_{s}\left(F_{3}, E\right)\right) \neq\left(F_{3}, E\right)$.

Theorem 3.9. Let $(X, \tau, E)$ be a soft topological space. Then.

(1) The closure of a soft open set is a soft regular closed set.

(2) The interior of a soft closed set is a soft regular open set.

Proof. (1) Let $(F, E)$ be a soft open set of a soft topological space $(X, \tau, E$. Clearly,

$\operatorname{Int}_{s}\left(C l_{s}(F ; E) \sqsubseteq(F, E), \quad\right.$ implies that $C l_{s}\left(\operatorname{Int}_{s}\left(C l_{s}(F ; E)\right)\right) \subseteq C l_{s}(F, E)$, . Now,

the fact that $(F, E)$ is a soft open set implies that $(F, E)$ 드 $\operatorname{Int}_{s}\left(C l_{s}(F ; E), \quad\right.$ and $\left.C l_{s}(F, E) \subseteq C l_{s} I n t_{s}\left(C l_{s}(F ; E)\right)\right)$.

Thus $C l_{S}(F ; E)$ is a soft regular closed set.

(2) Let $(F, E)$ be a soft closed set of a soft topological space $(X, \tau, E)$. Clearly, $\operatorname{Int}_{s}(F, E) \subseteq C l_{S} \operatorname{Int}_{s}(F, E)$. implies that $\operatorname{Int}_{s}(F, E) \subseteq \operatorname{Int}_{s} C l_{s} \operatorname{Int}_{s}(F, E)$. Now, the fact that $(F, E)$ is a soft closed set implies that $C l_{s} \operatorname{Int}_{s}(F, E) \sqsubseteq(F, E) \quad$ and $\quad \operatorname{Int}_{s} \operatorname{Cl}_{s} \operatorname{Int}_{s}(F, E) \sqsubseteq$ $\operatorname{Int}_{s}(F, E)$. Thus $\operatorname{Int}_{S}(F, E)$ is a soft regular open set.

Remark 3.10. In a soft topological space $(X, \tau, E)$, the collection of all soft regularly open sets forms a base for some topology $\tau_{s}$ on $(X, E)$.

Definition 3.11. In a soft topological space $(X, \tau, E)$, if $\tau_{s}$ coincides with $\tau$, then $\tau$ is said to be a soft semi 
regularization topology.

\section{Soft $\delta$-open Set And Soft $\delta$-closed Set}

In this section, we define soft $\delta$-open set, soft $\delta$-closed set, soft $\delta$-interior set and, and, soft $\delta$-closure set and investigate their related properties.

Definition 4.1. A soft set $(U, E)$ is soft $\delta$-open set if for each $e_{F} \in(U, E)$, there exists a soft regular open set $(G, E)$ such that $e_{F} \in(G, E) \subseteq(U, E)$, denoted by $(U, E) \in S \delta O(X, E)$ i.e. A soft set is soft $\delta$-open set if it is the union of soft regular open sets. The complement of soft $\delta$-open set is said to be soft $\delta$-closed set, denoted by $\left(U^{C}, E\right) \in S \delta C(X, E)$.

Proposition 4.2. The family $\tau_{\delta}$ of all soft $\delta$-open sets defines a soft topology on $X$. Soft $\delta$-topology on $X$ if the following axioms are true.

(1) $0_{E}, 1_{E} \in \tau_{\delta}$.

(2) If $\left(U_{1}, E\right),\left(U_{2}, E\right) \in \tau$, then $\left(U_{1}, E\right) \sqcap\left(U_{2}, E\right) \in \tau_{\delta}$.

(3) If $(G i, E) \in \tau_{\delta}$ for every $i \in I$, then $\sqcup(G i, E): i \in$ I\} $\in \tau_{\delta}$.

Proof. (1) It obvious that $0_{E}, 1_{E} \in \tau_{\delta}$.

(2) Let $\left(U_{1}, E\right),\left(U_{2}, E\right) \in \tau_{\delta}$. We prove that $\left(U_{1}, E\right) \sqcap$ $\left(U_{2}, E\right) \in \tau_{\delta}$. Let $e_{F} \in\left(U_{1}, E\right) \sqcap\left(U_{2}, E\right)$. Then $e_{F} \in\left(U_{1}, E\right)$ and $e_{F} \in\left(U_{2}, E\right)$. There exists $\left(G_{1}, E\right),\left(G_{2}, E\right) \in$ $\operatorname{SOR}(X, E)$ such that $e_{F} \in\left(G_{1}, E\right) \sqsubseteq\left(U_{1}, E\right)$ and $e_{F} \in$ $\left(G_{2}, E\right) \sqsubseteq\left(U_{2}, E\right)$. Then $e_{F} \in\left(G_{1}, E\right) \sqcap\left(G_{2}, E\right) \sqsubseteq\left(U_{1}, E\right) \sqcap$ $\left(U_{2}, E\right)$. But $\left(G_{1}, E\right) \sqcap\left(G_{2}, E\right) \in \operatorname{SRO}(X, E)$.

Then $\left(U_{1}, E\right) \sqcap\left(U_{2}, E\right) \in \tau_{\delta}$

(3) Let Let $\left\{\left(F_{i}, E\right), i \in I\right\} \in \tau_{\delta}$. We prove that $\sqcup$ $\left\{\left(F_{i}, E\right), i \in I\right\} \in \tau_{\delta}$. Let $e_{F} \in \sqcup\left\{\left(F_{i}, E\right), i \in I\right\}$.Then $e_{F} \in$ $\left\{\left(F_{i}, E\right), i \in I\right\}$ and there exists exists $(G, E) \in \operatorname{SOR}(X, E)$ such that $e_{F} \in(G, E) \sqsubseteq\left\{\left(F_{i}, E\right), i \in I\right\}$ Since $\left\{\left(F_{i}, E\right), i \in\right.$ $I\} \sqsubseteq \sqcup\left\{\left(F_{i}, E\right), i \in I\right\} . \quad$ Then $e_{F} \in(G, E) \sqsubseteq \sqcup\left\{\left(F_{i}, E\right), i \in\right.$ I $\}$ Thus $\left\{\left(F_{i}, E\right), i \in I\right\} \in \tau_{\delta}$.

Proposition 4.3. A soft regularly open set is soft $\delta$-open set in a soft topological space $(X, \tau, E)$.

Proof. The proof follows from the definitions.

Remark 4.4. A soft $\delta$-open set need not be soft regular open set in a soft topological space $(X, \tau, E)$

Example 4.5. The soft topological space is same in Example 3.2. We get $\tau_{\delta}=\left\{0_{E}, 1_{E},\left(F_{1}, E\right),\left(F_{2}, E\right),\left(F_{3}, E\right)\right\}$ be a soft $\delta$-topological space. We have $\left(F_{3}, E\right)$ is a soft $\delta$-open set but it is not a soft regular open set because $\operatorname{Int}_{s}\left(C l_{s}\left(F_{3}, E\right)\right) \neq\left(F_{3}, E\right)$.

Proposition 4.6. The following statement is true.

(1) $\tau_{\delta} \sqsubseteq \tau$

(2) $\tau \sqsupseteq \tau_{\delta} \sqsupseteq\left(\tau_{\delta}\right)_{\delta} \sqsupseteq\left(\left(\tau_{\delta}\right)_{\delta}\right)_{\delta} \sqsupseteq \cdots$

Proof. (1) Let $(F, E) \in \tau_{\delta}$ 2. There exists $(G, E) \in$ $\operatorname{SRO}(X, E)$ such that $e_{F} \in(G, E) \sqsubseteq(F, E)$; But $(G, E)$ is a soft open set. We get $(F, E)$ is neighborhood of $e_{F}$. Thus $(F, E) \in \tau$.

(2) Follows by part (1) and Proposition 4.2.

Remark 4.7. Soft regularly open set $\Rightarrow$ soft $\delta$-open set $\Longrightarrow$ soft open set, but the converse in no case is true.

Remark 4.8. It can be observed that for any soft topological space $(X, \tau, E)$, the topologies $\tau, \tau_{s}$ and $\tau_{\delta}$ are different and moreover $\tau_{s} \sqsubseteq \tau_{\delta} \sqsubseteq \tau$. It is clear that in a semi regularization space the above three topologies coincide, since $\tau_{s}=\tau$ in that case.

Proposition 4.9. Let $(X, \tau, E)$ be a soft topological space. The family $\tau_{\delta}^{c}$, has the following properties.

(1) $0_{E}, 1_{E} \in \tau_{\delta}^{c}$.

(2) If $(G, E),(H, E) \in \tau_{\delta}^{c}$, then $(G, E) \sqcup(H, E) \in \tau_{\delta}^{c}$.

(3) If $(G i, E) \in \tau_{\delta}^{c}$ for every $i \in I$, then $\Pi(G i, E): i \in$ I\} $\in \tau_{\delta}^{c}$.

Proof. The proof verify directly from the proposition 4.2: and (propositions 2.10 and 2.12 of(Georgiou \& Megaritis, 2014)).

Definition 4.10. A soft set $(G, E)$ in a soft $\delta$-topological space $\left(X, \tau_{\delta}, E\right)$, is called a soft $\delta$-neighborhood (briey: $\delta-\mathrm{snbd})$ of a soft point $e_{F} \in \boldsymbol{S P}(\boldsymbol{X})$ if there exists a soft $\delta$-open set $(H, E)$ such that $e_{F} \in(H, E) \sqsubseteq(G, E)$. The soft $\delta$-neighborhood

system of a soft point $e_{F}$, denoted by $N_{\tau_{\delta}}\left(e_{F}\right)$, is the family of all of its soft $\delta$-neighborhoods. 
Proposition 4.11. Let $\left(X, \tau_{\delta}, E\right)$ be soft topological space ,$(U, E) \in S S(X)_{E}$. Then $(U, E)$ is soft $\delta$-open set if only if $(U, E) \in N_{\tau_{\delta}}\left(e_{F}\right)$ for every $e_{F} \in(U, E)$.

Proof. Let $(U, E) \in S \delta O(X, E)$ and $e_{F} \in(U, E)$ Thus $e_{F} \in$ $(U, E) \subseteq(U, E)$. And then $(U, E) \in N_{\tau_{\delta}}\left(e_{F}\right)$ for every $e_{F} \in(U, E)$

Conversely Let $(U, E) \in N_{\tau_{\delta}}\left(e_{F}\right)$ for every $e_{F} \in(U, E)$, there exists a soft $\delta$-open set $(H, E)_{e_{F}}$ such that $e_{F} \in$ $(H, E)_{e_{F}} \sqsubseteq(U, E)$. Therefore $(U, E)=\sqcup(H, E)_{e_{F}}: e_{F} \in$ $(U, E),(H, E)_{e_{F}} \in \tau_{\delta}$. Then $(U, E) \in S \delta O(X, E)$

Proposition 4.12. Let $\left(X, \tau_{\delta}, E\right)$ be soft topological space, $(U ; E),(G, E) \in S S(X, E)$. Then

(1) If $(G, E) \in N_{\tau_{\delta}}\left(e_{F}\right)$. Then $e_{F} \in(G, E)$.

(2) If $(G, E),(U, E) \in N_{\tau_{\delta}}\left(e_{F}\right)$ then $(G, E) \sqcap(U, E) \in$ $N_{\tau_{\delta}}\left(e_{F}\right)$.

(3) If $(G, E) \in N_{\tau_{\delta}}\left(e_{F}\right)$ and $(G, E) \subseteq(U, E)$ then $(U, E) \in$ $N_{\tau_{\delta}}\left(e_{F}\right)$.

Proof. (1) Obvious.

(2) Pick $(G, E),(U, E) \in N_{\tau_{\delta}}\left(e_{F}\right)$. There exists $\left(H_{1}, E\right),\left(H_{2}, E\right) \in S \delta O(X, E)$, such that $e_{F} \in\left(H_{1}, E\right) \sqsubseteq$ $(G, E)$, and $e_{F} \in\left(H_{1}, E\right) \sqsubseteq(U, E)$. Then $e_{F} \in\left(H_{1}, E\right) \sqcap$ $\left(H_{2}, E\right) \subseteq(G, E) \sqcap(U, E)$. Thus $(G, E) \sqcap(U, E) \in N_{\tau_{\delta}}\left(e_{F}\right)$

(3) Let $(G, E) \in N_{\tau_{\delta}}\left(e_{F}\right), \quad(G, E) \sqsubseteq(U, E)$. There exists $(H, E) \in S \delta O(X, E)$, such that $e_{F} \in(H, E) \sqsubseteq(G, E)$. Hence $e_{F} \in(H, E) \sqsubseteq(G, E) \sqsubseteq(U, E)$.Then $(U, E) \in N_{\tau_{\delta}}\left(e_{F}\right)$.

Definition 4.13. Let $(G, E)$ be a soft set of topological space $\left(X, \tau_{\delta}, E\right)$. A soft point $e_{F}$ is called soft $\delta$-interior point of $(G, E)$ if there exists a soft $\delta$-open set $(U, E)$ such that $e_{F} \in(U, E) \sqsubseteq(G, E)$. The set of all soft $\delta$-interior points of $(G, E)$ is called the soft $\delta$-interior of $(G, E)$ and is denoted by $\operatorname{Int}_{s}^{\delta}(G, E)$.

In other words a soft point $e_{F}$ is called its soft $\delta$-interior point if $(G, E)$ is the $\delta$-snbd of the soft point $e_{F}$.So mean that $\operatorname{Int}_{S}^{\delta}(G, E) \in \tau_{\delta}$.

Proposition 4.14. Let $\left(X, \tau_{\delta}, E\right)$ be a soft topological space and $(H, E),(G, E),(U, E) \in S S(X, E)$. Then the following statements are true.

(1) $\operatorname{Int}_{s}^{\delta}(U, E) \sqsubseteq(U, E)$.

(2) $\operatorname{Int}_{s}^{\delta}(U, E)=\sqcup\left\{\left(H_{i}, E\right) \in \tau_{\delta},\left(H_{i}, E\right) \sqsubseteq(U, E)\right\}$.

(3) $\operatorname{Int}_{S}^{\delta}(U, E)$ is the largest soft $\delta$-open set contained in $(U, E)$.

(4) $(U, E)$ is soft $\delta$-open set if and only if $\operatorname{Int}_{S}^{\delta}(U, E)=$ $(U, E)$.

(5) $\operatorname{Int} t_{S}^{\delta}\left(0_{E}\right)=0_{E}$ and $\operatorname{Int} t_{S}^{\delta}\left(1_{E}\right)=1_{E}$.

(6) $\operatorname{Int}_{s}^{\delta}\left(\operatorname{Int} t_{s}^{\delta}(U, E)\right)=\operatorname{Int} t_{s}^{\delta}(U, E)$

(7) If $(H, E) \subseteq(G, E)$, then $\operatorname{Int}_{s}^{\delta}(H, E) \subseteq \operatorname{Int}_{s}^{\delta}(G, E)$.

(8) $\operatorname{Int}_{s}^{\delta}(H, E) \sqcup \operatorname{Int}_{S}^{\delta}(G, E) \sqsubseteq \operatorname{Int}_{S}^{\delta}((H, E) \sqcup(G, E))$.

$$
\operatorname{Int}_{s}^{\delta}(H, E) \sqcap \operatorname{Int} t_{s}^{\delta}(G, E)=\operatorname{Int} t_{s}^{\delta}((H, E) \sqcap(G, E)) .
$$

Proof. (1) Obvious.

(2) If $\left.e_{F} \in \sqcup_{i \in I}\left\{\left(H_{i}, E\right),\right\} \in \tau_{\delta},\left(H_{i}, E\right) \subseteq(U, E)\right\}$. Then $e_{F} \in\left(H_{1}, E\right) \subseteq(U, E)$, showing that $e_{F}$ is a soft $\delta$-interior point of $(U, E)$ and so $e_{F} \in \operatorname{Int} t_{S}^{\delta}(U, E)$. Thus $\left.\sqcup_{i \in I}\left\{\left(H_{i}, E\right),\right\} \in \tau_{\delta},\left(H_{i}, E\right) \sqsubseteq(U, E)\right\} \sqsubseteq \operatorname{Int}_{s}^{\delta}(U, E)$ Conversely, let $e_{F} \in \operatorname{Int} t_{S}^{\delta}(U, E)$, then $e_{F}$ is a soft $\delta$-interior point of $(U, E)$, there exists $\left(H_{1}, E\right) \in \tau_{\delta}$ such that $\quad e_{F} \in\left(H_{1}, E\right) \subseteq(U, E), \quad$ Consequently $e_{F} \in$ $\left.\sqcup_{i \in I}\left\{\left(H_{i}, E\right),\right\} \in \tau_{\delta},\left(H_{i}, E\right) \sqsubseteq(U, E)\right\} . \quad$ Therefore $\left.\operatorname{Int}_{S}^{\delta}(U, E) \sqsubseteq \sqcup_{i \in I}\left\{\left(H_{i}, E\right),\right\} \in \tau_{\delta},\left(H_{i}, E\right) \sqsubseteq(U, E)\right\} . \quad W e$ are done

(3) By (2) above $\operatorname{Int}_{s}^{\delta}(U, E)=\sqcup_{i \in I}\left\{\left(H_{i}, E\right),\right\} \in$ $\left.\tau_{\delta},\left(H_{i}, E\right) \sqsubseteq(U, E)\right\}$. Thus $\operatorname{Int}_{s}^{\delta}(U, E) \mathrm{s}$ is a soft $\delta$-open set soft subset of $(U, E)$. Now let $(H, E) \in \tau_{\delta}$ and $e_{F} \in(H, E)$ then $e_{F} \in(H, E) \sqsubseteq(U, E)$. Therefore $e_{F}$ is a soft interior point of $(U, E)$.Thus $e_{F} \in(H, E) \sqsubseteq$ $\operatorname{Int} t_{S}^{\delta}(U, E)$ which shows that every soft $\delta$-open soft subset of $(U, E)$ is contained in $\operatorname{Int}_{S}^{\delta}(U, E)$. Hence $\operatorname{Int}_{S}^{\delta}(U, E)$ is the largest soft $\delta$-open set contained in $(U, E)$.

(4) Let $(U, E)$ is soft $\delta$-open set. Then a soft $\delta$-open set containing all of its soft points, it follows that every soft point of $(U, E)$ is a soft $\delta$-interior of $(U, E)$. Thus $\operatorname{Int}_{S}^{\delta}(U, E) \subseteq(U, E)$ Let $e_{F} \in \operatorname{Int}_{S}^{\delta}(U, E)$ there exists $(H, E) \in \tau_{\delta}$ such that $e_{F} \in(H, E) \subseteq(U, E)$ then $e_{F} \in$ 
$\operatorname{Int} t_{S}^{\delta}(U, E) \sqsubseteq(U, E) \quad$ Therefore $\quad \operatorname{Int}_{S}^{\delta}(U, E)=(U, E)$ Conversely, since $\operatorname{Int}_{S}^{\delta}(U, E)=(U, E)$, then $(U, E) \in \tau_{\delta}$. Hence $(U, E)$ is soft $\delta$-open set if and only if $\operatorname{Int}_{s}^{\delta}(U, E)=(U, E)$.

(5) Is obvious.

(6) Since $\operatorname{Int}_{S}^{\delta}(U, E) \in S \delta O(X, E)$ is soft $\delta$-open set. We have $\quad \operatorname{Int}_{s}^{\delta} \operatorname{Int} t_{s}^{\delta}(U, E)=\operatorname{Int} t_{s}^{\delta}(U, E)$

(7) Let $e_{F} \in \operatorname{Int}_{S}^{\delta}(H, E)$ there exists $(U, E) \in \tau_{\delta}$ soft containing $e_{F}$ such that

$(U, E) \subseteq(H ; E)$. But $(H, E) \subseteq(G, E)$. Then $(U, E) \subseteq$ $(G ; E)$. which implies that

$e_{F} \in \operatorname{Int}_{S}^{\delta}(G, E)$. Thus $\operatorname{Int}_{s}^{\delta}(H, E) \subseteq \operatorname{Int}_{S}^{\delta}(G, E)$

(8) Since $(H, E) \subseteq(H, E) \sqcup(G, E)$. We have $\operatorname{Int}_{s}^{\delta}(H, E) \subseteq$ $\operatorname{Int}_{S}^{\delta}((H, E) \sqcup(G, E))$ and $(H, E) \sqsubseteq(H, E) \sqcup(G, E)$. Then $\operatorname{Int}_{S}^{\delta}(G, E) \sqsubseteq \operatorname{Int}_{S}^{\delta}((H, E) \sqcup(G, E))$ Therefore $\operatorname{Int}_{S}^{\delta}((H, E) \sqcup(G, E))=\operatorname{Int} t_{S}^{\delta}(H, E) \sqcup \operatorname{Int}_{S}^{\delta}(G, E)$.

(9) Since $(H, E) \sqcap(G, E) \sqsubseteq(H ; E)$. Then $\operatorname{Int}_{s}^{\delta}((H, E) \sqcap$ $(G, E)) \subseteq \operatorname{Int} t_{S}^{\delta}(H ; E)$

Also $\operatorname{Int}_{S}^{\delta}((H, E) \sqcap(G, E)) \subseteq \operatorname{Int}_{S}^{\delta}(G ; E)$

We get $\operatorname{Int} t_{s}^{\delta}((H, E) \sqcap(G, E)) \sqsubseteq \operatorname{Int}_{S}^{\delta}(H ; E) \sqcap \operatorname{Int} t_{s}^{\delta}(G ; E)$. Conversely, let $e_{F} \in \operatorname{Int} t_{S}^{\delta}(H ; E) \sqcap \operatorname{Int} t_{S}^{\delta}(G ; E)$. So that $e_{F} \in \operatorname{Int}_{S}^{\delta}(H ; E)$ and $e_{F} \in \operatorname{Int}_{S}^{\delta}(G ; E)$. There exists two soft $\delta$-open set $\left(U_{1}, E\right),\left(U_{2}, E\right)$ soft containing $e_{F}$ such that $\left(U_{1}, E\right) \subseteq(H, E)$, and $\left(U_{2}, E\right) \subseteq(G, E)$ Implies that $\left(U_{1}, E\right) \sqcap\left(U_{2}, E\right)=(U, E) \in S \delta O(X, E), \quad$ and $\quad e_{F} \in$ $(U, E) \sqsubseteq(H, E) \sqcap(G, E) .(\mathrm{U} ; \mathrm{E})$ Then $e_{F} \in \operatorname{Int} t_{s}^{\delta}((H, E) \sqcap$ $(G, E))$. We get $\quad \operatorname{Int}_{s}^{\delta}(H, E) \sqcap \operatorname{Int}_{s}^{\delta}(G, E) \sqsubseteq$ $\operatorname{Int}_{S}^{\delta}((H, E) \sqcap(G, E)) . \quad$ Therefor $\quad \operatorname{Int}_{s}^{\delta}(H, E) \sqcap$ $\operatorname{Int} t_{S}^{\delta}(G, E)=\operatorname{Int}_{S}^{\delta}((H, E) \sqcap(G, E))$. The following example shows that the equalities do not hold in Proposition 4.14(8).

Example 4.15. The soft topological space $(X, \tau, E)$ is the same as in Example 3.2:

Suppose that $(U, E)=\left\{\left(e_{1},\left\{h_{1}\right\}\right),\left(e_{2},\left\{h_{1}, h_{3}\right\}\right)\right\} \quad$ and $(G, E)=\left\{\left(e_{1},\left\{h_{2}, h_{3}\right\}\right),\left(e_{2},\left\{h_{1}, h_{2}\right\}\right)\right\}$. One can deduce that $\operatorname{Int} t_{s}^{\delta}(H, E) \sqcup \operatorname{Int}_{s}^{\delta}(G, E)=\operatorname{Int} t_{s}^{\delta}((H, E) \sqcup(G, E))$. and $\operatorname{Int}_{s}^{\delta}(H, E) \sqcap \operatorname{Int} t_{s}^{\delta}(G, E) \neq \operatorname{Int} t_{s}^{\delta}((H, E) \sqcap(G, E))$.

Corollary 4.16. Let $\left(X, \tau_{\delta}, E\right)$ be a soft topological space, and $(U, E) \in S S(X, E)$. Then

$$
\begin{gathered}
\operatorname{Int}_{s}^{\delta}(U, E)=\sqcup\left\{\left(H_{i}, E\right):\left(H_{i}, E\right) \sqsubseteq(U, E),\left(H_{i}, E\right)\right. \\
\in \operatorname{SRO}(X, E)\} .
\end{gathered}
$$

Definition 4.17. Let $(X, \tau, E)$ be a soft topological space and $e_{F} \in S P(X)$ is said to be a soft $\delta$-cluster point of $(F, E) \in S S(X, E)$ if for every a soft regular open $(U, E)$ soft containing of $e_{F}$ we have $(F, E) \sqcap(U ; E) \neq 0_{E}$. The set of all soft $\delta$-cluster points of $(G, E)$ is called the soft $\delta$-closure denoted by $C l_{S}^{\delta}(G, E)$

Remark 4.18. Let $(X, \tau, E)$ be a soft topological space and $(F, E) \in(X ; E)$, then.

$$
\begin{gathered}
C l_{S}^{\delta}(F, E)=\sqcap\left\{\left(H_{i}, E\right):(F, E) \sqsubseteq\left(H_{i}, E\right),\left(H_{i}, E\right)\right. \\
\in \operatorname{SRC}(X, E)\} .
\end{gathered}
$$

Proposition 4.19. Let $(X, \tau, E)$ be a soft topological space over $X$ and $(V, E),(F, E) \in S S(X, E)$. Then

(1) $C l_{S}^{\delta}(V, E) \in S \delta C(X, E)$.

(2) $(V, E) \subseteq C l_{s}^{\delta}(V, E)$.

(3) $(V, E)$ is soft $\delta$-closed set if and only if $C l_{s}^{\delta}(V, E)=$ $(V, E)$.

(4) $C l_{s}^{\delta}(F, E)=\Pi\left\{\left(H_{i}, E\right) \in S \delta C(X, E),(F, E) \sqsubseteq\left(H_{i}, E\right)\right\}$.

(5) $C l_{S}^{\delta}\left(0_{E}\right)=0_{E}$ and $C l_{S}^{\delta}\left(1_{E}\right)=1_{E}$.

(6) $\left.C l_{s}(V, E)\right) \sqsubseteq C l_{s}^{\delta}(V, E)$.

(7) $C l_{s}^{\delta} C l_{s}^{\delta}(F, E)=C l_{s}^{\delta}(F, E)$

(8) If $(V, E) \subseteq(F, E)$, then $C l_{S}^{\delta}(V, E) \subseteq C l_{S}^{\delta}(F, E)$.

(9) $C l_{s}^{\delta}(V, E) \sqcup C l_{s}^{\delta}(G, E)=C l_{s}^{\delta}((V, E) \sqcup(G, E))$.

(10) $C l_{s}^{\delta}((H, E) \sqcap(V, E)) \sqsubseteq C l_{s}^{\delta}(H, E) \sqcap C l_{s}^{\delta}(V, E)$.

The following example shows that the equalities do not hold in Proposition 4.19(9)

Example 4.20. The soft topological space $(X, \tau, E)$ is the same as in Example 3.2. Suppose $(H, E)=$ $\left\{\left(e_{1},\left\{h_{2}\right\}\right),\left(e_{2},\left\{h_{2}\right\}\right)\right\}$ and $(M, E)=\left\{\left(e_{1},\left\{h_{1}\right\}\right),\left(e_{2},\left\{h_{3}\right\}\right)\right\}$ $C l_{s}^{\delta}(H, E)=\left\{\left(e_{1},\left\{h_{2}, h_{3}\right\}\right),\left(e_{2},\left\{h_{2}, h_{3}\right\}\right)\right\}, \quad C l_{s}^{\delta}(\mid M, E)=$ $\left\{\left(e_{1},\left\{h_{1}, h_{3}\right\}\right),\left(e_{2},\left\{h_{1}, h_{3}\right\}\right)\right\}, \quad C l_{s}^{\delta}((H, E) \sqcap(M, E))=$ $C l_{S}^{\delta}\left(0_{E}\right)=0_{E} . \quad$ Therefore $\quad C l_{S}^{\delta}(H, E) \sqcap C l_{S}^{\delta}(M, E) \nsubseteq$ $C l_{s}^{\delta}((H, E) \sqcap(M, E))$ 
Proposition 4.21. Let $(X, \tau, E)$ be a soft topological space, and $(G ; E) \in S S(X, E)$. Then.

(1) $C l_{S}^{\delta}\left(V^{c}, E\right)=\left(\operatorname{Int}_{S}^{\delta}(V, E)\right)^{c}$

(2) $\left(C l_{s}^{\delta}(V, E)\right)^{c}=\operatorname{Int} t_{s}^{\delta}\left(V^{c}, E\right)$.

(3) $\operatorname{Int}_{s}^{\delta}(V, E)=\left(C l_{s}^{\delta}\left(V^{c}, E\right)\right)^{c}$

Proof. (1) We prove that ) $\left.C l_{s}^{\delta}\left(V^{c}, E\right)\right) \subseteq\left(\operatorname{Int}_{s}^{\delta}(V, E)\right)^{c}$ Let $e_{F} \in C l_{S}^{\delta}\left(V^{c}, E\right)$. Then, for every soft regular open set $(U, E)$ containing of $e_{F}$, we have $\left(V^{c}, E\right) \sqcap(U, E) \neq$ $0_{E}$. Then the relation $(U, E) \subseteq(V, E)$ is not true. Therefore $e_{F} \notin \operatorname{Int} t_{S}^{\delta}(V, E)$. Then $e_{F} \in\left(\operatorname{Int} t_{S}^{\delta}(V, E)\right)^{c}$ thus $C l_{s}^{\delta}\left(V^{c}, E\right) \subseteq\left(\operatorname{Int}_{s}^{\delta}(V, E)\right)^{c}$

Conversely, we prove that $\left.\operatorname{Int} t_{s}^{\delta}(V, E)\right)^{c} \subseteq C l_{s}^{\delta}\left(V^{c}, E\right)$. Let $e_{F} \in\left(\operatorname{Int} t_{S}^{\delta}(V, E)\right)^{c}$ and $e_{F} \notin \operatorname{In} t_{S}^{\delta}(V, E)$. There $(U, E)$ be a soft regular open set containing of $e_{F}$. such

that $e_{F} \in(U, E) \subseteq\left(V^{c}, E\right)$ therefore have $\left(V^{c}, E\right) \sqcap$ $(U, E) \neq 0_{E}$. Thus, $e_{F} \in C l_{S}^{\delta}\left(V^{c}, E\right)$.

We gets $\left.\operatorname{Int} t_{s}^{\delta}(V, E)\right)^{c} \sqsubseteq C l_{s}^{\delta}\left(V^{c}, E\right)$. Therefore $l_{s}^{\delta}\left(V^{c}, E\right)=$ $\left(\operatorname{Int}_{s}^{\delta}(V, E)\right)^{c}$. $(V, E)\})^{c}=\sqcup\left\{\left(H_{i}^{c}, E\right) \in S \delta O(X, E),\left(V^{c}, E\right) \subseteq\left(H_{i}^{c}, E\right)\right\}=$ $\operatorname{Int} t_{S}^{\delta}\left(V^{c}, E\right)$

(3) Obvious.

\section{Soft $\boldsymbol{\delta}$-Boundary and Soft $\boldsymbol{\delta}$-Exterior}

Definition 5.1. Let $(X, \tau, E)$ be a soft topological space and $(F, E)$ be a soft set

over $X$. The soft $\delta$-boundary of soft set $(F, E)$ over $X$ is denoted by $B d_{S}^{\delta}(F, E)$ and is defined as $B d_{S}^{\delta}(F, E)=$ $C l_{s}^{\delta}(F, E) \sqcap C l_{s}^{\delta}\left(F^{c}, E\right)$.

Remark 5.2. From the above definition it follows directly that the soft sets $(F, E)$ and $\left(F^{c}, E\right)$ have same soft $\delta$-boundary.

Proposition 5.3. Let $(X, \tau, E)$ be a soft topological space, $(F, E) \in S S(X, E)$. Then the following statements are true.

(1) $B d_{s}^{\delta}(F, E)=C l_{s}^{\delta}(F, E) \backslash \operatorname{Int} t_{s}^{\delta}(F, E)$.

(2) $B d_{s}^{\delta}(F, E) \sqcap \operatorname{Int}_{s}^{\delta}(F, E)=0_{E}$.

(3) $(F, E) \sqcup B d_{s}^{\delta}(F, E)=C l_{s}^{\delta}(F, E)$
Proof. (1)

$$
C l_{s}^{\delta}(F, E) \backslash \operatorname{Int}_{s}^{\delta}(F, E) \quad=C l_{s}^{\delta}(F, E) \sqcap
$$

$\left(\operatorname{Int}_{s}^{\delta}(F, E)\right)^{c}=C l_{s}^{\delta}(F, E) \sqcap C l_{s}^{\delta}\left(F^{c}, E\right)=B d_{S}^{\delta}(F, E)$.

(2) ) $B d_{s}^{\delta}(F, E) \sqcap \operatorname{Int} t_{s}^{\delta}(F, E)=C l_{s}^{\delta}(F, E) \sqcap C l_{s}^{\delta}\left(F^{c}, E\right) \sqcap$ $\operatorname{Int}_{s}^{\delta}(F, E)=C l_{s}^{\delta}(F, E) \sqcap C l_{s}^{\delta}\left(F^{c}, E\right) \sqcap\left(C l_{s}^{\delta}(F, E)\right)^{c}=$ $C l_{s}^{\delta}(F, E) \sqcap\left(C l_{s}^{\delta}\left(F^{c}, E\right) \sqcap\left(C l_{s}^{\delta}(F, E)\right)^{c}\right)=C l_{s}^{\delta}(F, E) \sqcap$

$0_{E}=0_{E}$.

$$
\left((F, E) \sqcup B d_{s}^{\delta}(F, E)=(F, E) \sqcup C l_{s}^{\delta}(F, E) \sqcap\right.
$$

$C l_{S}^{\delta}\left(F^{c}, E\right)=\left((F, E) \sqcup C l_{S}^{\delta}(F, E)\right) \sqcap(F, E) \sqcup C l_{S}^{\delta}\left(F^{c}, E\right)=$ $C l_{s}^{\delta}(F, E) \sqcap\left((F, E) \sqcup C l_{s}^{\delta}\left(F^{c}, E\right) \sqsupseteq C l_{s}^{\delta}(F, E) \sqcap\right.$ $\left.\left((F, E) \sqcup\left(F^{c}, E\right)\right)\right)=C l_{S}^{\delta}(F, E) \sqcap 1_{E}=C l_{S}^{\delta}(F, E)$.

Theorem 5.4. Let $(X, \tau, E)$ be a soft topological space, $(F, E) \in S S(X, E)$. Then $B d_{S}^{\delta}(F, E)=0_{E}$ if and only if $(F, E)$ is soft $\delta$-closed set and soft $\delta$-open set .

Proof. Suppose that $B d_{S}^{\delta}(F, E)=0_{E}$ First, we prove that $(F, E)$ is soft $\delta$-closed set. We have $B d_{S}^{\delta}(F, E)=0_{E}$ or $C l_{S}^{\delta}(F, E) \sqcap C l_{S}^{\delta}\left(F^{c}, E\right)=0_{E} \quad$ Hence $C l_{S}^{\delta}(F, E) \sqsubseteq$ $\left(C l_{s}^{\delta}\left(F^{c}, E\right)\right)^{c}=\operatorname{Int}_{s}^{\delta}(F, E)$. Therefore $C l_{S}^{\delta}(F, E) \sqsubseteq(F, E)$, and so $(F, E)$ is soft $\delta$-closed set. Now, we prove that $(F, E)$ is soft $\delta$-open set. Indeed, we have $B d_{S}^{\delta}(F, E)=0_{E}$ or $C l_{S}^{\delta}(F, E) \sqcap C l_{S}^{\delta}\left(F^{c}, E\right)=0_{E}$. Hence $(F, E) \sqcap\left(\operatorname{Int} t_{S}^{\delta}(F, E)\right)^{c}=0_{E}, \quad$ and $\quad$ so $\quad(F, E) \sqsubseteq$ $\operatorname{Int}_{S}^{\delta}(F, E)$. Therefore $(F, E)$ is soft $\delta$-open set. Conversely, suppose that $(F, E)$ is soft $\delta$-closed set and soft $\delta$-open set. Then $B d_{s}^{\delta}(F, E)=C l_{S}^{\delta}(F, E) \sqcap$ $C l_{s}^{\delta}\left(F^{c}, E\right)=C l_{s}^{\delta}(F, E) \sqcap I n t_{s}^{\delta}(F, E)=(F, E) \sqcap(F, E)=$ $0_{E}$

Theorem 5.5. Let $(X, \tau, E)$ be a soft topological space, $(F, E) \in S S(X, E)$, then

(1) $(F, E)$ is soft $\delta$-open set if and only if $(F, E) \sqcap$ $B d_{S}^{\delta}(F, E)=0_{E}$

(2) $\left((F, E)\right.$ is soft $\delta$ - closed set if and only if $B d_{S}^{\delta}(F, E) \sqsubseteq$ $(F, E)$

Proof. (1) Let $(F, E)$ is soft $\delta$-open set. Then $\operatorname{Int}_{S}^{\delta}(F, E)=(F, E)$. Implies that $(F, E) \sqcap B d_{S}^{\delta}(F, E)=0_{E}$ Conversely, suppose

that $(F, E) \sqcap B d_{S}^{\delta}(F, E)=0_{E}$ Then $(F, E) \sqcap\left(C l_{S}^{\delta}(F, E) \sqcap\right.$ 
$\left.C l_{S}^{\delta}\left(F^{c}, E\right)\right)=0_{E}$ or

Then $\left((F, E) \sqcap C l_{S}^{\delta}(F, E)\right) \sqcap C l_{S}^{\delta}\left(F^{c}, E\right)=0_{E}$ Then $(F, E) \sqcap$ $C l_{S}^{\delta}(F, E)=0_{E} \quad$ which implies that $(F, E) \sqsubseteq$ $\left(C l_{s}^{\delta}(F, E)\right)^{c}=\operatorname{Int}_{s}^{\delta}(F, E)$. Moreover, $\operatorname{Int}_{s}^{\delta}(F, E) \subseteq(F, E)$. Therefore $\operatorname{Int}_{S}^{\delta}(F, E)=(F, E)$. And thus $(F, E)$ is soft $\delta$-open set.

(2) Let $(F, E)$ be a soft $\delta$-closed set. Then $C l_{S}^{\delta}(F, E)=$ $(F, E)$. Now, $B d_{s}^{\delta}(F, E)=C l_{s}^{\delta}(F, E) \sqcap C l_{s}^{\delta}\left(F^{c}, E\right) \subseteq(F, E)$. That is, $B d_{S}^{\delta}(F, E) \sqsubseteq(F, E)$. Conversely, suppose that $B d_{S}^{\delta}(F, E) \sqsubseteq(F, E) . \quad$ Then $\quad B d_{S}^{\delta}(F, E) \sqcap\left(F^{c}, E\right)=0_{E}$. Since $d_{s}^{\delta}(F, E)=B d_{s}^{\delta}\left(F^{c}, E\right)$, we have Then $B d_{s}^{\delta}\left(F^{c}, E\right) \sqcap\left(F^{c}, E\right)=0_{E}$. By $(1),\left(F^{c}, E\right)$ is soft $\delta$-open set. Hence $(F, E)$ is soft $\delta$-closed set.

Proposition 5.6. Let $(X, \tau, E)$ be a soft topological space, $(F, E) \in S S(X, E)$. Then the following statements are true.

(1) $(F, E) \backslash B d_{s}^{\delta}(F, E)=\operatorname{Int}_{s}^{\delta}(F, E)$.

2) $\operatorname{If}(F, E)$ is soft $\delta$-closed set, then $(F, E) \backslash \operatorname{Int} t_{S}^{\delta}(F, E)=$ $B d_{S}^{\delta}(F, E)$

Proof. (1)We have $(F, E) \backslash B d_{S}^{\delta}(F, E)=(F, E) \sqcap$ $\left(B d_{s}^{\delta}(F, E)\right)^{c}=(F, E) \sqcap\left(\left(C l_{s}^{\delta}(F, E) \sqcap C l_{s}^{\delta}\left(F^{c}, E\right)\right)^{c}\right)$

$$
\begin{aligned}
& =(F, E) \sqcap\left(\left(C l_{S}^{\delta}(F, E) \sqcap\left(\operatorname{Int} t_{s}^{\delta}(F, E)\right)^{c}\right)^{c}\right) \\
& =(F, E) \sqcap\left(C l_{s}^{\delta}(F, E)\right)^{c} \sqcup\left((F, E) \sqcap \operatorname{Int} t_{s}^{\delta}(F, E)\right) \\
& \quad=0_{E} \sqcup \operatorname{Int}_{S}^{\delta}(F, E)=\operatorname{Int}_{S}^{\delta}(F, E)
\end{aligned}
$$

(2) Since $(F, E)$ is soft $\delta$-closed set, $C l_{S}^{\delta}(F, E)=(F, E)$. Therefore $(F, E) \backslash \operatorname{Int}_{S}^{\delta}(F, E)=C l_{s}^{\delta}(F, E) \backslash \operatorname{Int} t_{s}^{\delta}(F, E)=$ $B d_{s}^{\delta}(F, E)$

Definition 5.7. Let $(X, \tau, E)$ be a soft topological space and $(F, E) \in S S(X, E)$. The $\delta$-exterior of $(F, A)$ is the soft set. $\operatorname{Ext}_{s}^{\delta}(F, E)=\operatorname{Int} t_{s}^{\delta}\left(F^{c}, E\right)$ is said to be a soft $\delta$-exterior of $(F, A)$.

Theorem 5.8. Let $(X, \tau, E)$ be a soft topological space and $(F, E),(G, E) \in S S(X, E)$. Then the following statements hold.

(1) $\operatorname{Ext}_{s}^{\delta}(F, E) \sqsubseteq \operatorname{Ext}(F, E)$ is soft $\delta$-open set.

(2) $\operatorname{Ext}_{s}^{\delta}(F, E)$ is soft $\delta$-open set.
(3) $\operatorname{Ext}_{s}^{\delta}(F, E)=0_{E} \backslash C l_{s}^{\delta}(F, E)$.

(4) $\operatorname{Ext}_{s}^{\delta}\left(\operatorname{Ext}_{s}^{\delta}(F, E)\right)=\operatorname{Int} t_{s}^{\delta}\left(C l_{s}^{\delta}(F, E)\right)$.

(5) If $(F, E) \sqsubseteq(G, E)$, then $\operatorname{Ext}_{s}^{\delta}(F, E) \sqsupseteq \operatorname{Ext}_{s}^{\delta}(G, E)$.

(6) $\operatorname{Ext}_{s}^{\delta}((F, E) \sqcup(G, E))=\operatorname{Ext}_{s}^{\delta}(F, E) \sqcap \operatorname{Ext}_{s}^{\delta}(G, E)$.

(7) $\operatorname{Ext}_{s}^{\delta}(F, E) \sqcap E x t_{s}^{\delta}(G, E) \sqsubseteq \operatorname{Ext}_{s}^{\delta}((F, E) \sqcap(G, E))$

(8) $\operatorname{Ext}_{S}^{\delta}\left(0_{E}\right)=0_{E}$, and $\operatorname{Ext} t_{S}^{\delta}\left(1_{E}\right)=1_{E}$

(9) $\operatorname{Ext}_{s}^{\delta}\left(\left(E x t_{s}^{\delta}(F, E)\right)^{c}\right)=E x t_{s}^{\delta}(F, E)$

(10) $\operatorname{Ext}_{s}^{\delta}(F, E) \sqcup \operatorname{Ext}_{s}^{\delta}(F, E) \sqsubseteq E x t_{s}^{\delta}((F, E) \sqcap(G, E))(11)$ $\operatorname{Int}_{s}^{\delta}(F, E) \sqsubseteq E x t_{s}^{\delta}\left(E x t_{s}^{\delta}(F, E)\right)$.

Proof. (1) $\quad \operatorname{Ext}_{s}^{\delta}(F, E)=\operatorname{Int} t_{s}^{\delta}\left(F^{c}, E\right) \sqsubseteq \operatorname{Int}_{s}\left(F^{c}, E\right)=$ $\operatorname{Ext}_{s}(F, E)$.

(2) Since $\operatorname{Int}_{s}^{\delta}(F, E)$ is soft $\delta$-open set Then $\operatorname{Ext}_{s}^{\delta}(F, E)$ is soft $\delta$-open set.

(3) Obvious

$$
\operatorname{Ext}_{s}^{\delta}\left(\operatorname{Ext}_{s}^{\delta}(F, E)\right)=\operatorname{Int} t_{s}^{\delta}\left(\operatorname{Ext}_{s}^{\delta}(F, E)\right)^{c}=
$$

$\operatorname{Int} t_{s}^{\delta}\left(\operatorname{Int} t_{s}^{\delta}\left(F^{c}, E\right)\right)^{c}=\operatorname{Int} t_{s}^{\delta}\left(C l_{s}^{\delta}(F, E)\right)$.

(5) If $(F, E) \subseteq(G, E)$ then $\left(G^{c}, E\right) \subseteq\left(F^{c}, E\right)$ and $\operatorname{Int} t_{s}^{\delta}\left(F^{c}, E\right) \sqsupseteq \operatorname{Int} t_{S}^{\delta}\left(G^{c}, E\right)$. Thus $\operatorname{Ext}_{S}^{\delta}(F, E) \sqsupseteq \operatorname{Ext}_{s}^{\delta}(G, E)$

$$
\operatorname{Ext}_{S}^{\delta}((F, E) \sqcup(G, E))=\operatorname{Int} t_{s}^{\delta}((F, E) \sqcup(G, E))^{c}=
$$
$\operatorname{Int}_{S}^{\delta}\left(\left(F^{c}, E\right) \sqcap\left(G^{c}, E\right)\right)=\operatorname{Int} t_{S}^{\delta}\left(F^{c}, E\right) \sqcap \operatorname{Int} t_{S}^{\delta}\left(G^{c}, E\right)=$ $\operatorname{Ext}_{s}^{\delta}(F, E) \sqcap \operatorname{Ext}_{s}^{\delta}(G, E)$

(7) $\operatorname{Ext}_{s}^{\delta}(F, E) \sqcap E x t_{s}^{\delta}(G, E)=\operatorname{Int} t_{s}^{\delta}\left(F^{c}, E\right) \sqcap$ $\operatorname{Int}_{S}^{\delta}\left(G^{c}, E\right) \sqsubseteq \operatorname{Int} t_{s}^{\delta}\left(\left(F^{c}, E\right) \sqcap\left(G^{c}, E\right)\right)=\operatorname{Int} t_{s}^{\delta}((F, E) \sqcap$ $(G, E))^{C}$ $=\operatorname{Ext}_{s}^{\delta}((F, E) \sqcup(G, E)) \sqsubseteq \operatorname{Ext}_{s}^{\delta}((F, E) \sqcap(G, E))$

(8), (9),(10) are obvious.

(11) $\operatorname{Int}_{s}^{\delta}(F, E) \sqsubseteq \operatorname{Int}_{s}^{\delta}\left(C l_{s}^{\delta}(F, E)\right)=\operatorname{Int}_{s}^{\delta}\left(\operatorname{Int} t_{s}^{\delta}\left(F^{c}, E\right)\right)^{c}$.

$=\operatorname{Int}_{s}^{\delta}\left(\operatorname{Ext}_{s}^{\delta}(F, E)\right)^{c}=\operatorname{Ext}_{s}^{\delta}\left(E x t_{s}^{\delta}(F, E)\right)$.

The following example shows that the equalities do not hold in Proposition 5.8 (7),(10) and (11).

Example 5.9. In Example $3.2(1)$, we obtain $\operatorname{Ext}_{S}^{\delta}(F, E) \sqcap$ $\operatorname{Ext}_{s}^{\delta}(G, E) \sqsubseteq \operatorname{Ext}_{s}^{\delta}((F, E) \sqcap(G, E))$ and $\operatorname{Ext}_{s}^{\delta}(F, E) \sqcap$ $\operatorname{Ext}_{S}^{\delta}(G, E) \neq \operatorname{Ext}_{s}^{\delta}((F, E) \sqcap(G, E)$. Similarly, we find That (2) $\quad \operatorname{Ext}_{s}^{\delta}(F, E) \sqcup E x t_{s}^{\delta}(F, E) \sqsubseteq E x t_{s}^{\delta}((F, E) \sqcap$ $(G, E)), \quad$ but $\operatorname{Ext}_{s}^{\delta}(F, E) \sqcup \operatorname{Ext}_{s}^{\delta}(F, E) \neq \operatorname{Ext}_{s}^{\delta}((F, E) \sqcap$ 
$(G, E))$. In Example 3.2 (3), we have $\operatorname{Int}_{S}^{\delta}(F, E)$ 드 $\operatorname{Ext}_{s}^{\delta}\left(\operatorname{Ext}_{s}^{\delta}(F, E)\right)$.

\section{Soft $f_{P u}-\delta$-continuity}

In this section, we introduce the notion of soft $f_{P u}-$ $\delta$-continuity of functions induced by two mappings $u$ : $X \rightarrow Y$ and $p: E \rightarrow B$ on soft topological spaces $(X, \tau, E)$ and $\left(Y, \tau^{*}, B\right)$

Definition 6.1. Let $(X, \tau, E)$ and $\left(Y, \tau^{*}, B\right)$ be two soft topological spaces, $u: X \rightarrow Y$ and $p: E \rightarrow B$ be mappings, and $e_{F} \in S P(X)$. The map $f_{P u}: \operatorname{SS}(X, E) \rightarrow$ $\mathrm{SS}(\mathrm{Y}, \mathrm{B})$ is soft $f_{P u}-\delta$-continuous at $e_{F}$ if for each $(G, B)$ neighborhood $e_{F}$, there exists a $(H, E)$ neighborhood $e_{F}$ such that $f_{P u}\left(\operatorname{Int}_{S}\left(C l_{S}(H, E)\right) \sqsubseteq\right.$ $\left(\operatorname{Int}_{s}\left(C l_{s}(G, B)\right)\right.$.

Theorem 6.2. For the mapping $f_{P u}: \mathrm{SS}(\mathrm{X}, \mathrm{E}) \rightarrow$ $\mathrm{SS}(\mathrm{Y}, \mathrm{B})$, the following properties are equivalent.

(1) $f_{P u}$ is soft $\delta$-continuous.

(2) For each $e_{F} \in S P(X)$. and each soft regular open set $(V, B)$ containing $f_{P u}\left(e_{F}\right)$, there exists a soft regular open set $(U, E)$ containing $e_{F}$ such that $f_{P u}(U, E) \subseteq(V, E)$.

(3) $f_{P u} C l_{S}^{\delta}(A, E) \sqsubseteq C l_{s}^{\delta} f_{P u}(A, E)$ for every $(A, E) \in$ $S S(X, E)$.

(4) $C l_{s}^{\delta} f_{p u}^{-1}(N, B) \sqsubseteq f_{p u}^{-1} C l_{s}^{\delta}(N, B)$ for every $(N, B) \in$ $S S(Y, B)$.

(5) For each soft $\delta$-closed set $(V, B) \in S \delta C(Y, B)$, $f_{p u}^{-1}(V, B) \in S \delta C(X, E)$.

(6) For each soft $\delta$-open set $(V, B) \in S \delta O(Y, B)$, $f_{p u}^{-1}(V, B) \in S \delta O(X, E)$.

(7) For each soft regular open set $(V, B) \in S S(Y, B)$, $f_{p u}^{-1}(V, B) \in S \delta O(X, E)$.

(8) For each soft regular closed set set $(N, B) \in S S(Y, B)$, $f_{p u}^{-1}(N, B) \in S \delta C(X, E)$.

Proof. (1) $\Rightarrow$ (2): Directly from Definition 6.1.

(2) $\Rightarrow(3)$ : Let $e_{F} \in S P(X)$ and $(A, E) \in S S(X, E)$ such that $f_{P u}\left(e_{F}\right) \in f_{P u} C l_{S}^{\delta}(A, E)$. Suppose that $f_{P u}\left(e_{F}\right) \neq$
$f_{P u} C l_{S}^{\delta}(A, E)$. Then, there exists a soft regular open set neighborhood $(V, B)$ of $f_{P u}\left(e_{F}\right)$ such that $f_{P u}(A, E) \sqcap$ $(V, B)=0_{B}$. By (2), there exists a soft regular open set neighborhood $(U, E)$ of $\left(e_{F}\right)$ such that $f_{P u}(U, E)$ 드 $(V, E)$. Since $f_{P u}(A, E) \sqcap f_{P u}(U, E) \sqsubseteq f_{P u}(A, E) \sqcap(V, B)=$ $0_{B}, f_{P u}(A, E) \sqcap f_{P u}(U, E)$. Hence, we get that $(A, E) \sqcap$ $(U, E) \sqsubseteq f_{p u}^{-1}\left(f_{P u}(A, E)\right) \sqcap f_{p u}^{-1}\left(f_{P u}(U, E)\right)=$

$f_{p u}^{-1}\left(f_{P u}(A, E) \sqcap f_{P u}(U, E)\right)=0_{B}$. Hence we have $(U, E) \sqcap$ $(A, E)=0_{E}$, and $\left(e_{F}\right) \notin C l_{S}^{\delta}(A, E)$. This shows that $f_{P u}\left(e_{F}\right) \in f_{P u} C l_{s}^{\delta}(A, E)$. This is a contradiction.

Therefore, we obtain that $f_{P u}\left(e_{F}\right) \in C l_{S}^{\delta}\left(f_{P u}(A, E)\right)$

$(3) \Rightarrow(4)$ : Let $(N, B) \in S S(Y, B)$ such that $(A, E)=$ $f_{p u}^{-1}(N, B) . \quad$ By $\quad(3), \quad f_{P u}\left(C l_{s}^{\delta}\left(f_{p u}^{-1}(N, B)\right)\right)$ 드 $C l_{s}^{\delta}\left(f_{P u}\left(f_{p u}^{-1}(N, B)\right)\right) \sqsubseteq C l_{s}^{\delta}(N, B)$. From here, we have $C l_{s}^{\delta}\left(f_{p u}^{-1}(N, B)\right) \sqsubseteq f_{p u}^{-1}\left(C l_{s}^{\delta}\left(f_{P u}\left(f_{p u}^{-1}(N, B)\right)\right)\right) \sqsubseteq$ $f_{p u}^{-1}\left(C l_{s}^{\delta}(N, B)\right)$. Thus we obtain $C l_{s}^{\delta}\left(f_{p u}^{-1}(N, B)\right) \sqsubseteq$ $f_{p u}^{-1}\left(C l_{s}^{\delta}(N, B)\right)$.

$(4) \Rightarrow(5)$ : $\quad$ Let $\quad(V, B) \in S \delta C(Y, B)$. By $\quad(4)$, $C l_{s}^{\delta}\left(f_{p u}^{-1}(V, B)\right) \subseteq f_{p u}^{-1}\left(C l_{s}^{\delta}(V, B)\right)=f_{p u}^{-1}(V, B)$.

and ever $f_{p u}^{-1}(V, B) \sqsubseteq C l_{s}^{\delta}\left(f_{p u}^{-1}(V, B)\right)$. Hence that $C l_{s}^{\delta}\left(f_{p u}^{-1}(V, B)\right)=f_{p u}^{-1}(V, B) . \quad$ This shows that $f_{p u}^{-1}(V, B) \in S \delta C(X, E)$.

$(5) \Rightarrow(6): \quad$ Let $\quad(V, B) \in S \delta O(Y, B) . \quad \operatorname{Then}\left(V^{c}, B\right) \in$ $S \delta C(Y, B)$. By (5), $f_{p u}^{-1}\left(V^{c}, B\right)=\left(f_{p u}^{-1}(V, B)\right)^{c} \in S \delta C(Y, B)$ . Therefore, $f_{p u}^{-1}\left(V^{c}, B\right) \in S \delta C(Y, B)$.

$(6) \Rightarrow(7)$ : Let $(V, B) \in S R O(Y, B)$. Since every a soft regular open set is soft $\delta$-open set, $(V, B) \in S \delta O(Y, B)$. By $(6), f_{p u}^{-1}(V, B) \in S \delta O(X, E)$

$(7) \Rightarrow(8): \quad$ Let $(N, B) \in \operatorname{SRC}(Y, B)$. Then $\left(N^{c}, B\right) \in$ $\operatorname{SRO}(Y, B)$. By (7), $\quad f_{p u}^{-1}\left(N^{c}, B\right)=\left(f_{p u}^{-1}(N, B)\right)^{c} \in$ $S \delta O(X, E)$. Therefore $f_{p u}^{-1}(N, B) \in S \delta C(X, E)$.

(8) $\Rightarrow(1): \quad$ Let $e_{F} \in S P(X) . \quad$ and $(A, B) \in S R O(Y, B)$ such that $f_{P u}\left(e_{F}\right) \in(A, E)$. Now, then $\left(A^{c}, B\right) \in$ 
$S R C(Y, B) . \quad$ By $\quad(8), \quad f_{p u}^{-1}\left(A^{c}, B\right)=\left(f_{p u}^{-1}(A, B)\right)^{c} \in$ $S \delta C(X, E)$. Thus, $f_{p u}^{-1}(A, B) \in S \delta O(X, E)$. Since $\left(e_{F}\right) \in$ $f_{p u}^{-1}(A, B)$. Then there exists $(U, E) \in$ $S R O(Y, B)$ such that $e_{F} \in(U, E) \subseteq f_{p u}^{-1}(A, B)$. Hence $f_{P u}\left(\operatorname{Int}_{s}\left(C l_{s}(U, E)\right) \sqsubseteq\left(\operatorname{Int}_{s}\left(C l_{s}(A, B)\right)\right.\right.$. This shows that $f_{P u}$ is a soft $\delta$-continuous mapping.

Theorem 6.3. For the mapping $f_{P u}: \mathrm{SS}(\mathrm{X}, \mathrm{E}) \rightarrow \mathrm{SS}(\mathrm{Y}, \mathrm{B})$, the following properties are equivalent.

(1) $f_{P u}$ is soft $\delta$-continuous.

(2) $f_{p u}^{-1} \operatorname{Int} t_{s}^{\delta}(U, B) \sqsubseteq \operatorname{Int} t_{s}^{\delta} f_{p u}^{-1}(U, B)$ for every $(U, B) \in$ $\operatorname{SS}(Y, B)$.

Proof. (1) $\Rightarrow(2)$ :Let $f_{P u}$ is soft $\delta$-continuous and $(U, B) \in S S(Y, B)$. Implies that $C l_{s}^{\delta} f_{p u}^{-1}\left(U^{c}, B\right) \sqsubseteq f_{p u}^{-1} C l_{s}^{\delta}\left(U^{c}, B\right)$. Then $f_{p u}^{-1} \operatorname{Int}_{s}^{\delta}(U, B)=f_{p u}^{-1}\left(C l_{s}^{\delta}\left(U^{c}, B\right)\right)^{c}=$ $\left(f_{p u}^{-1}\left(C l_{s}^{\delta}\left(U^{c}, B\right)\right)\right)^{c} \subseteq\left(C l_{s}^{\delta}\left(f_{p u}^{-1}\left(U^{c}, B\right)\right)\right)^{c}=$ $C l_{s}^{\delta}\left(f_{p u}^{-1}\left(U^{c}, B\right)\right)^{c}=\operatorname{Int} t_{s}^{\delta} f_{p u}^{-1}(U, B)$.

\section{References}

1. Ali, M. I., Feng, F., Liu, X., Min, W. K., \& Shabir, M. (2009). On some new operations in soft set theory. Computers $\mathcal{E}$ Mathematics with Applications, 57(9), 1547-1553.

2. Aygünoğlu, A., \& Aygün, H. (2012). Some notes on soft topological spaces. Neural computing and Applications, 21(1), 113119.

3. Çağman, N., Karataş, S., \& Enginoglu, S. (2011). Soft topology. Computers \& Mathematics with Applications, 62(1), 351-358.

4. Ergül, Z. G., Yüksel, S., \& Tozlu, N. (2014). On Soft Generalized Preregular Closed and Open Sets in Soft Topological Spaces. Applied Mathematical Sciences, 8(158), 7875-7884.

5. Georgiou, D. N., \& Megaritis, A. (2014). Soft set theory and topology. Applied General Topology, 15(1), 93-109.

6. Hussain, S., \& Ahmad, B. (2011). Some properties of soft topological spaces. Computers \& Mathematics with Applications, 62(11), 4058-4067. doi: http://dx.doi.org/10.1016/j.camwa.2011.09.051

7. Maji, P., Biswas, R., \& Roy, A. R. (2003). Soft set theory. Computers \& Mathematics with Applications, 45(4), 555-562.

8. Min, W. K. (2011). A note on soft topological spaces. Computers E Mathematics with Applications, 62(9), 3524-3528.

9. Molodtsov, D. (1999). Soft set theory-first results. Computers $\mathcal{E}$ Mathematics with Applications, 37(4), 19-31.
(2) $\Rightarrow$ (1): We prove that $f_{P u}(U, B) \in S \delta O(X, E)$ for every $(U, B) 2 S \delta O(Y, B)$. Let $(U, B) \in S \delta O(Y, B)$, then $\operatorname{Int} t_{s}^{\delta}(U, B)=(U, B) . \quad$ Therefore, $\quad f_{p u}^{-1}(U, B)=$ $f_{p u}^{-1}\left(\operatorname{Int} t_{s}^{\delta}(U, B)\right) \subseteq \operatorname{Int} t_{s}^{\delta}\left(f_{p u}^{-1}(U, B)\right)$. We have $\operatorname{Int} t_{s}^{\delta}\left(f_{p u}^{-1}(U, B)\right) \sqsubseteq f_{p u}^{-1}(U, B)$. Thus $\quad \operatorname{Int} t_{s}^{\delta}\left(f_{p u}^{-1}(U, B)\right)=$ $f_{p u}^{-1}(U, B)$, which means that $f_{p u}^{-1}(U, B) \in S \delta O(X, E)$.

Implies that $f_{P u}$ is soft $\delta$-continuous.

\section{Conclusion}

All over the globe, soft set theory is a topic of interest for many authors working in diverse areas due to its rich potential for applications in several directions. So, we found it reasonable to extend some known concept in general topology to the soft topological structures. In this paper, several characterizations of soft $\delta$-topology in terms of soft $\delta$-open sets are introduced and the concept of soft $f_{P u}-\delta$-continuity is obtained. Thus we fill a gap in the existing literature on soft topology.

10. Molodtsov, D. (2001). The description of a dependence with the help of soft sets. J. Comput. Sys. Sc. Int, 40(6), 977-984.

11. Molodtsov, D. (2004). The theory of soft sets: URSS Publishers, Moscow.

12. Molodtsov, D., Leonov, V. Y., \& Kovkov, D. (2006). Soft sets technique and its application. Nechetkie Sistemy i Myagkie Vychisleniya, 1, 8-39.

13. Peyghan, E., Samadi, B., \& Tayebi, A. About soft topological spaces. Topology and its Applications, In Press, (2012).

14. Shabir, M., \& Naz, M. (2011). On soft topological spaces. Computers \& Mathematics with Applications, 61(7), 1786-1799.

15. Zorlutuna, I., Akdag, M., Min, W., \& Atmaca, S. (2012). Remarks on soft topological spaces. Annals of Fuzzy Mathematics and Informatics, 3(2), 171-185. 